\title{
Combined amperometric/field-effect sensor for the detection of dissolved hydrogen
}

\author{
C. Huck ${ }^{a, b}$, A. Poghossian ${ }^{a, b}$, P. Wagner ${ }^{c}$, M.J. Schöning ${ }^{a, b, *}$ \\ a Institute of Nano- and Biotechnologies (INB), Aachen University of Applied Sciences, Campus Jülich, 52428 Jülich, Germany \\ b Peter Grünberg Institute (PGI-8), Forschungszentrum Jülich GmbH, 52525 Jülich, Germany \\ ${ }^{\mathrm{c}}$ Institute for Materials Research (IMO), Hasselt University, 3590 Diepenbeek, Belgium
}

\section{A R T I C L E I N F O}

\section{Article history:}

Available online 17 October 2012

\section{Keywords:}

Dissolved hydrogen

Amperometric gas sensor

Field-effect sensor

Biogas

\begin{abstract}
A B S T R A C T
Real-time and reliable monitoring of the biogas process is crucial for a stable and efficient operation of biogas production in order to avoid digester breakdowns. The concentration of dissolved hydrogen $\left(\mathrm{H}_{2}\right)$ represents one of the key parameters for biogas process control. In this work, a one-chip integrated combined amperometric/field-effect sensor for monitoring the dissolved $\mathrm{H}_{2}$ concentration has been developed for biogas applications. The combination of two different transducer principles might allow a more accurate and reliable measurement of dissolved $\mathrm{H}_{2}$ as an early warning indicator of digester failures. The feasibility of the approach has been demonstrated by simultaneous amperometric/fieldeffect measurements of dissolved $\mathrm{H}_{2}$ concentrations in electrolyte solutions. Both, the amperometric and the field-effect transducer show a linear response behaviour in the $\mathrm{H}_{2}$ concentration range from 0.1 to $3 \%(\mathrm{v} / \mathrm{v})$ with a slope of $198.4 \pm 13.7 \mathrm{nA} / \%(\mathrm{v} / \mathrm{v})$ and $14.9 \pm 0.5 \mathrm{mV} / \%(\mathrm{v} / \mathrm{v})$, respectively.
\end{abstract}

(c) 2012 Elsevier B.V. All rights reserved.

\section{Introduction}

A stable and efficient operation of the biogas production has the potential to replace some of the limited fossil fuels [1]. The use of biogas as energy source is currently establishing in the group of alternative energies. In general, the natural process of anaerobic digestion is a relative stable system that occurs in nature without the need for precise process control. However, under high loading conditions, process failures such as disadvantageous biogas yield or stoppage of the biogas production due to acidification of the medium are known to occur [2-4]. Therefore, real-time and reliable controlling and monitoring of the biogas process is crucial for a stable and efficient operation of biogas production in order to avoid digester breakdowns.

The concentration of dissolved hydrogen $\left(\mathrm{H}_{2}\right)$ represents one of the most important parameters for biogas process control in anaerobic digesters $[5,6]$. Accumulated $\mathrm{H}_{2}$ strongly inhibits the degradation of volatile fatty acids, such as propionate and butyrate, resulting in a consequent deterioration of normal operation [7]. A build-up of hydrogen above a critical concentration of higher than $0.04 \mu \mathrm{M}$ has been reported as initial stage of digester overloading $[7,8]$. If hydrogen production exceeds the maximum ability of

\footnotetext{
* Corresponding author at: Institute of Nano- and Biotechnologies (INB), Aachen University of Applied Sciences, Campus Jülich, 52428 Jülich, Germany. Tel.: +492416009 53215; fax: +49241600953235.

E-mail address: schoening@fh-aachen.de (M.J. Schöning).
}

the methanogenic biomass to degrade hydrogen, there will be a rapid and large increase in the hydrogen concentration prior to digester failures. Thus, dissolved hydrogen is a key factor in the intricate balance between microbial species involved in the multistep degradation during anaerobic digestion, making it a useful parameter for biogas process monitoring and early warning of process disturbances [2,3,9-12].

Most of hydrogen sensors, used for monitoring the anaerobic biogas production, are based on the detection of $\mathrm{H}_{2}$ in the gas phase of the digester [5,13-15]. Dissolved $\mathrm{H}_{2}$ in the liquid medium is thus calculated from the gas fraction, assuming that the hydrogen-transfer rate between the gas and the liquid phase is not limited. However, $\mathrm{H}_{2}$ mass-transfer coefficients in anaerobic digesters are much smaller than those typically found in aerobic fermentation digesters [16]. That is because the culture broth of anaerobic digestion consists of a complex physico-chemical composition with respect to the $\mathrm{H}_{2}$ solubility $[17,18]$. This limits the rapidity with which an increase in $\mathrm{H}_{2}$ concentration in the biomass can be detected in the gas phase of the digester. As a consequence, serious overloading of the digester may occur before the raised $\mathrm{H}_{2}$ concentration in the gas phase is detected. Therefore, having a practical, reliable and low-cost instrumentation that provides a continuous and in situ measurement of dissolved hydrogen in anaerobic digesters would be highly advantageous.

In this work, a Si-based combined chemosensor capable for the simultaneous amperometric/field-effect detection of the concentration of dissolved $\mathrm{H}_{2}$ has been developed for biogas applications. Such a combination of two different transducer principles for 
the detection of the same parameter might allow a more accurate, selective and reliable measurement of dissolved $\mathrm{H}_{2}$ as an early warning indicator of digester failures. The functioning of the developed one-chip integrated dual amperometric/field-effect chemosensor has been tested in electrolyte solutions with different concentrations of dissolved $\mathrm{H}_{2}$.

\section{Experimental}

\subsection{Structure and functioning principle of the combined $\mathrm{H}_{2}$ sensor}

The schematic layer structure of the combined dissolved $\mathrm{H}_{2}$ sensor and the measurement set-up for the simultaneous amperometric/field-effect detection of dissolved $\mathrm{H}_{2}$ in electrolyte solutions is shown in Fig. 1. The developed sensor combines a pH-sensitive capacitive EIS (electrolyte-insulator-semiconductor) sensor consisting of an $\mathrm{Al}-\mathrm{p}-\mathrm{Si}-\mathrm{SiO}_{2}-\mathrm{Ta}_{2} \mathrm{O}_{5}$ structure and two circular-type thin-film Pt electrodes. The specific feature of the combined $\mathrm{H}_{2}$-sensor chip is the implementation of the field-effect $\mathrm{pH}$ sensor in addition to well-known amperometric measurements. The field-effect $\mathrm{pH}$ sensor is a basic structural element of current chemical sensors and biosensors [19-25] and is used in this approach for an indirect detection of the dissolved $\mathrm{H}_{2}$ gas. This new approach has been introduced by the authors for the first time in [26]. Thus, two transduction principles are closely combined at the microscale, enabling new electrochemical detection opportunities.

The operation principle of the combined sensor structure is assumed to be as follows. Dissolved $\mathrm{H}_{2}$ diffuses to the polarized Pt working electrode and is electrochemically oxidized according to the following reaction $[27,28]$ :

$\mathrm{H}_{2} \rightarrow 2 \mathrm{e}^{-}+2 \mathrm{H}^{+}$

This causes a current depending on the dissolved hydrogen concentration. If the potential of the working electrode is adjusted (usually $+0.55 \mathrm{~V}$ vs. $\mathrm{Ag} / \mathrm{AgCl}$ reference electrode) that any hydrogen molecule reaching the electrode surface is immediately oxidized, then the current will be controlled solely by the diffusion rate of hydrogen to the electrode surface. The most important difference of our $\mathrm{H}_{2}$-sensor chip and other macro- or miniaturized

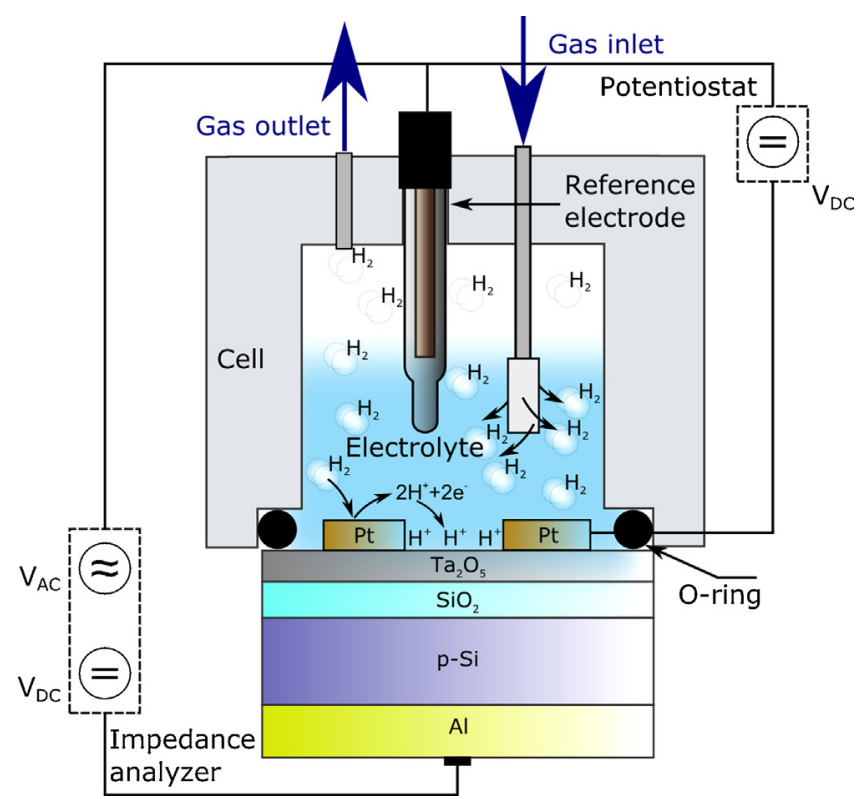

Fig. 1. Schematic structure and measurement set-up of the combined amperometric/field-effect dissolved $\mathrm{H}_{2}$ sensor. (a)

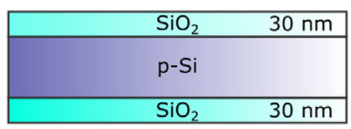

(b)

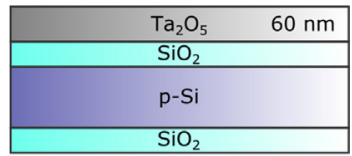

(c)

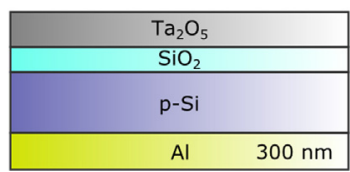

(d)

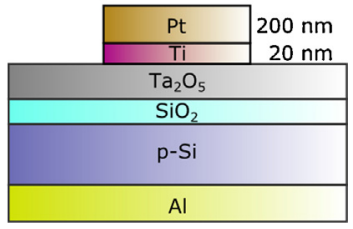

Fig. 2. Flowchart for the fabrication of the combined dissolved $\mathrm{H}_{2}$ sensor: (a) p-S wafer with thermally grown $\mathrm{SiO}_{2}$; (b) deposition of tantalum and thermal oxidation to $\mathrm{Ta}_{2} \mathrm{O}_{5}$; (c) etching of $\mathrm{SiO}_{2}$ on the rear side and deposition of the Al back-side contact; (d) deposition and patterning of the circular Pt thin-film electrodes.

amperometric $\mathrm{H}_{2}$ sensors reported in literature [15,27,29,30], is the existence of the one-chip integrated field-effect sensor, capable for an indirect detection of dissolved $\mathrm{H}_{2}$. The product of $\mathrm{H}_{2}$ oxidation, i.e., $\mathrm{H}^{+}$ions generated at the working electrode (see Eq. (1)), will diffuse to the $\mathrm{pH}$-sensitive gate-insulator surface (in this study, $\mathrm{Ta}_{2} \mathrm{O}_{5}$ ) and will be detected there. A resulting local $\mathrm{pH}$ decrease near the surface of the $\mathrm{pH}$-sensitive layer leads to a change in the surface charge and thus, modulates the space-charge capacitance in the Si and consequently, the flatband voltage and capacitance of the EIS structure. In previous experiments, field-effect devices have been successfully used for the detection of $\mathrm{H}^{+}$ions that have been electrochemically generated via electrolysis of water [31,32]. The output signal of the combined sensor is considered as " $\mathrm{H}_{2}$ signal" only, if the signal changes of both the amperometric and the field-effect sensor are nearly simultaneous (with a small delay time necessary for the diffusion of $\mathrm{H}^{+}$ions generated at the amperometric electrode to the gate region of the field-effect sensor) and if the signal of the field-effect sensor is shifted towards more negative potentials that corresponds to an increase of the $\mathrm{H}^{+}$concentration. In this way, the selectivity of the combined sensor to $\mathrm{H}_{2}$ detection can be achieved.

\subsection{Fabrication of the combined sensor structure}

The flowchart for the fabrication of the combined amperometric/field-effect $\mathrm{H}_{2}$ sensor is shown in Fig. 2. For the realization of the field-effect sensor, capacitive $\mathrm{Al}-\mathrm{Si}-\mathrm{SiO}_{2}-\mathrm{Ta}_{2} \mathrm{O}_{5}$ (p-Si, $\rho=1-10 \Omega \mathrm{cm} ; 30 \mathrm{~nm}$ thermally grown $\mathrm{SiO}_{2}$ (Fig. 2a)) structures with a $\mathrm{Ta}_{2} \mathrm{O}_{5}$ layer as $\mathrm{pH}$-sensitive gate insulator material have been fabricated. $\mathrm{Ta}_{2} \mathrm{O}_{5}$ is widely used for field-effect $\mathrm{pH}$ sensing, due to its high $\mathrm{pH}$ sensitivity [33] as well as high corrosion-resistance properties in a wide $\mathrm{pH}$ range [34]. The $\mathrm{Ta}_{2} \mathrm{O}_{5}$ films were prepared by means of thermal oxidation of an electron-beam deposited, $30 \mathrm{~nm}$ thick tantalum layer in dry oxygen atmosphere at $517^{\circ} \mathrm{C}$ for about $30 \mathrm{~min}$, yielding a $\sim 60 \mathrm{~nm}$ thick $\mathrm{Ta}_{2} \mathrm{O}_{5}$ layer (Fig. 2b). After etching the $\mathrm{SiO}_{2}$ from the rear side of the wafer, a $300 \mathrm{~nm}$ Al film was deposited as a contact layer for the field-effect sensor (Fig. 2c).

For the preparation of the amperometric transducer, a Pt layer with a thickness of $200 \mathrm{~nm}$ was deposited together with an adhesion layer of $20 \mathrm{~nm}$ Ti by means of electron-beam evaporation and patterned as circular electrodes via photolithography and lift-off technique, respectively (see Fig. 2d). Platinum has an excellent electro-catalytic activity for hydrogen oxidation as compared to other metals $[35,36]$. In a following step, the wafer was separated into single sensor chips with a size of $10 \mathrm{~mm} \times 14 \mathrm{~mm}$ and assembled onto a printed circuit board (PCB). For electrical connection of the field-effect sensor, the Al rear-side contact of the EIS structure was glued with electrically conductive adhesive onto the PCB 
substrate. The front-side contacts to the platinum electrodes were provided by means of an ultrasonic wedge bonder. Finally, the electrical contacts were encapsulated with silicone rubber.

\subsection{Measurement set-up}

For experiments, the PCB substrate with the combined dissolved $\mathrm{H}_{2}$ sensor was mounted into a home-made measuring cell as it is schematically shown in Fig. 1. The front side of the sensor chip was contacted by the electrolyte and a conventional liquid-junction $\mathrm{Ag} / \mathrm{AgCl}$ reference electrode (Metrohm). The sidewalls of the combined sensor chip were protected from the electrolyte solution by means of an O-ring, thereby circumventing the need for a complicated encapsulation process. The contact area of the combined sensor with the solution was about $0.4 \mathrm{~cm}^{2}$ in total. Since the response of the field-effect $\mathrm{pH}$ sensor is inversely proportional to the buffer capacity [37], the measurements were performed in a low-capacity buffer solution to obtain a high sensor signal. As electrolyte, a $0.25 \mathrm{mM}$ polymix multi-component buffer solution ( $\mathrm{pH} 7$ ) containing $100 \mathrm{mM}$ sodium chloride $(\mathrm{NaCl})$ as an ionic-strength adjuster was used $[38,39]$.

The test chamber was provided with a gas inlet and outlet. Hydrogen gas was dissolved in the electrolyte through a perforated tube. The required gas composition was obtained by mixing hydrogen and nitrogen in various ratios (from 0 to $3 \%(\mathrm{v} / \mathrm{v}), \mathrm{H}_{2}$ ) using commercial mass flow controllers (El-Flow, Bronkhorst High-Tech). The experiments were performed in a dark Faraday cage at room temperature $\left(\mathrm{ca} .22^{\circ} \mathrm{C}\right.$ ) and at a gas flow rate of $100 \mathrm{sccm}$.

The combined sensor has been characterized by means of amperometry using a potentiostat (PalmSens handheld potentiostat/galvanostat), and constant-capacitance (ConCap) method using an impedance analyzer (IM6, Zahner Elektrik). For the amperometric detection of dissolved $\mathrm{H}_{2}$, a standard two-electrode configuration under potential control was used. The potential was set at $+0.55 \mathrm{~V}$ vs. the $\mathrm{Ag} / \mathrm{AgCl}$ reference electrode and the hydrogen concentration-dependent current was sampled every second. The ConCap mode allows a dynamic characterization of the field-effect EIS sensor. In this mode, the capacitance of the EIS sensor is kept constant (usually within the depletion region of the capacitance-voltage curve at $\sim 60 \%$ of the maximum capacitance) using a feedback-control circuit, and potential changes at the transducer/electrolyte interface were directly monitored. For operation of the field-effect sensor, a DC (direct current) polarization voltage is applied via the reference electrode to set the working point of the EIS sensor, and a small AC (alternating current) voltage $(20 \mathrm{mV})$ is applied to the system in order to measure the capacitance of the sensor. All field-effect measurements were carried out at a frequency of $120 \mathrm{~Hz}$. A custom-made LabVIEW "virtual instrument" program (except 'program' in computers) was developed for experimental control and data acquisition.

\section{Results and discussion}

\section{1. $p H$ sensitivity of the capacitive EIS sensor}

Before the $\mathrm{H}_{2}$ experiments were performed, the $\mathrm{pH}$ sensitivity of the capacitive field-effect $\mathrm{p}-\mathrm{Si}-\mathrm{SiO}_{2}-\mathrm{Ta}_{2} \mathrm{O}_{5}$ structure has been characterized. Fig. 3 depicts a typical dynamic ConCap response of the EIS sensor recorded in Titrisol buffer solution with different $\mathrm{pH}$ values. The EIS sensor shows an average $\mathrm{pH}$ sensitivity of $57.4 \mathrm{mV} / \mathrm{pH}$ in the linear range from $\mathrm{pH} 3$ to 9 , which is in good agreement with $\mathrm{pH}$ sensitivity values reported in literature for a $\mathrm{Ta}_{2} \mathrm{O}_{5}$ layer $[34,40,41]$.

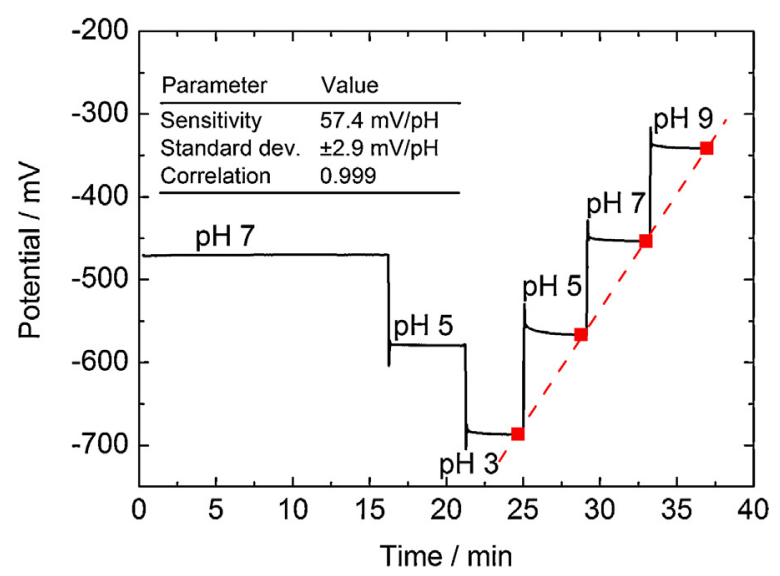

Fig. 3. Typical dynamic ConCap response of a capacitive p-Si-SiO${ }_{2}-\mathrm{Ta}_{2} \mathrm{O}_{5}$ fieldeffect EIS structure recorded in Titrisol buffer with different $\mathrm{pH}$ values from $\mathrm{pH}$ 3 to $\mathrm{pH} 9$ and corresponding calibration curve (inlet).

\subsection{Validation of independent functioning of the one-chip integrated field-effect and amperometric transducers}

The functioning principle of the pH-sensitive field-effect sensor is based on the detection of $\mathrm{pH}$-induced potential changes at the gate-insulator/electrolyte interface, whereas the amperometric detection relies on an electron-transfer reaction (reduction or oxidation) of an electro-active specimen at the working electrode. Since the developed dissolved $\mathrm{H}_{2}$ sensor combines both transducer principles, in separate experiments, the independent functioning of the field-effect and amperometric transducers integrated on one single chip has been investigated. For this, $\mathrm{HCl}$ was added to the measuring solution to stimulate a response of the field-effect sensor and simultaneously, to study the impact of $\mathrm{pH}$ changes on the amperometric signal. On the other hand, the well-known electrochemically reversible ferricyanide/ferrocyanide $\left(\left[\mathrm{Fe}(\mathrm{CN})_{6}\right]^{3-} /\left[\mathrm{Fe}(\mathrm{CN})_{6}\right]^{4-}\right)$ redox couple was used to clarify whether the signal of the field-effect transducer is affected by the electron-transfer reactions (without the proton generation) at the amperometric transducer or not. The results of these experiments are summarized in Fig. 4. Here, the time-dependent responses of the combined amperometric/field-effect sensor simultaneously recorded at different measuring conditions are depicted. The working electrode of the amperometric transducer was

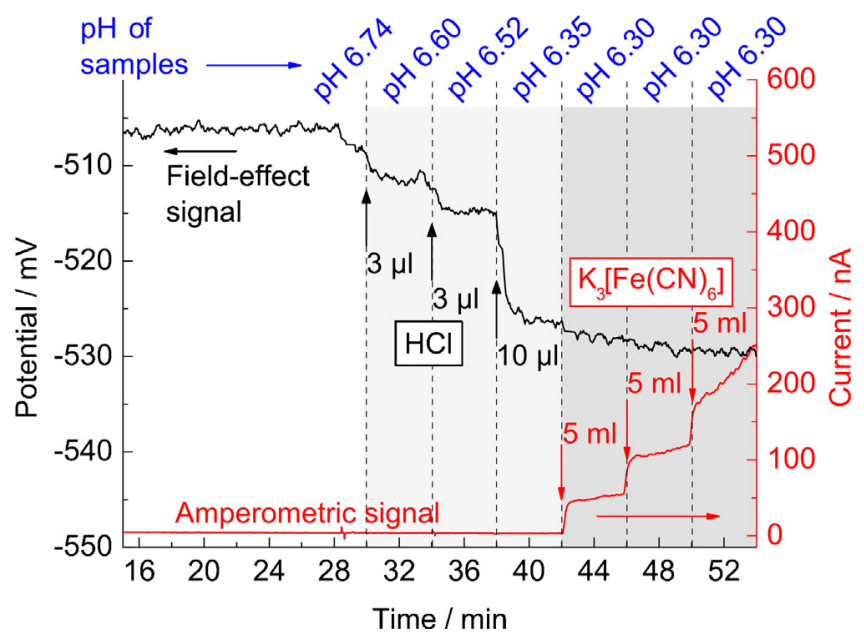

Fig. 4. Validation of independent functioning of the one-chip integrated field-effect and amperometric transducers. The $\mathrm{pH}$ value of samples was controlled with a conventional pH-glass electrode, simultaneously. 
polarized at a potential of $+0.4 \mathrm{~V}$ vs. the $\mathrm{Ag} / \mathrm{AgCl}$ reference electrode related to the reduction of $\left[\mathrm{Fe}(\mathrm{CN})_{6}\right]^{3-}$. A phosphate buffer ( $0.1 \mathrm{mM}, \mathrm{pH} 7$ ) adjusted with $100 \mathrm{mM} \mathrm{NaCl}$ was used as electrolyte solution and stirred continuously. The $\mathrm{pH}$ value of the electrolyte solution was monitored in addition with a conventional $\mathrm{pH}$-glass electrode (Metrohm).

During the start-up period of the experiment (initial $30 \mathrm{~min}$ ), both transducers show a stable response behaviour in phosphate buffer. After $30 \mathrm{~min}, 3 \mu \mathrm{l} \mathrm{HCl}$ was added to the electrolyte and the titration with $\mathrm{HCl}$ was repeated twice with titration volumes of $3 \mu \mathrm{l}$ (34 min) and $10 \mu \mathrm{l}(38 \mathrm{~min}) \mathrm{HCl}$. A total potential shift of $22 \mathrm{mV}$ towards more negative potential values was observed for the fieldeffect device, which corresponds to a $\mathrm{pH}$ decrease of $\Delta \mathrm{pH} \sim 0.4$. An additional analysis with a pH-glass electrode of samples drawn before and after each titration step confirmed this $\mathrm{pH}$ shift (see Fig. 4). On the contrary, the amperometric transducer shows a stable signal throughout this first part of the experiment and is therefore, not affected by the $\mathrm{pH}$ change of the solution.

In the next step, $5 \mathrm{ml}$ of potassium hexacyanoferrate(III) $\left(\mathrm{K}_{3}\left[\mathrm{Fe}(\mathrm{CN})_{6}\right]\right.$ ) was added to the solution (42 min, $46 \mathrm{~min}, 50 \mathrm{~min}$ ) to stimulate redox reactions at the $\mathrm{Pt}$ working electrode. As expected, the amperometric transducer responds immediately with an increase of the current of about $45 \mathrm{nA}$ after each addition of $\mathrm{K}_{3}\left[\mathrm{Fe}(\mathrm{CN})_{6}\right]$. At the same time, the field-effect sensor signal remains practically stable (some small changes in the ConCap response could be attributed to an intrinsic drift of the field-effect sensor), and thus, was not influenced by the current of the amperometric sensor. The results presented in Fig. 4 not only underline the functioning of the one-chip integrated field-effect and amperometric transducers, but also verify their independent functioning that is essential for further experiments on dissolved $\mathrm{H}_{2}$ detection with the combined sensor chip.

\subsection{Detection of dissolved $\mathrm{H}_{2}$ with the combined amperometric/field-effect sensor}

Fig. 5a demonstrates an example of a simultaneous amperometric/field-effect detection of dissolved $\mathrm{H}_{2}$ in the concentration range from 0.05 to $3 \%(\mathrm{v} / \mathrm{v}) \mathrm{H}_{2}$. The data were collected by exposing the combined sensor chip to the electrolyte with different concentrations of dissolved $\mathrm{H}_{2}$ for $10 \mathrm{~min}$. Prior to the introduction of a new hydrogen gas mixture, the electrolyte was flushed with nitrogen in order to remove the residual content of dissolved $\mathrm{H}_{2}$.

The amperometric sensor responded instantaneously to the $\mathrm{H}_{2}$ dosage with a $\mathrm{H}_{2}$ concentration-dependent increase of the output current. At the same time, the ConCap signal of the $\mathrm{pH}$-sensitive field-effect sensor shifted towards more negative potentials in response to an increasing hydrogen concentration. The negative signal shift in the ConCap mode corresponds to more positive gatesurface charges as a consequence of proton generation (see Eq. (1)) at the Pt electrode. The resulting $\mathrm{H}_{2}$ concentration-dependent local $\mathrm{pH}$ decrease near the surface of the $\mathrm{pH}$-sensitive layer modulates the flatband voltage and output signal of the field-effect EIS sensor. For instance, with the $1 \%(\mathrm{v} / \mathrm{v}) \mathrm{H}_{2}$ dosage, the output signal of the field-effect sensor shifts about $13.5 \pm 0.1 \mathrm{mV}$. Taking into account that the $\mathrm{pH}$ sensitivity of the $\mathrm{Ta}_{2} \mathrm{O}_{5}$-gate EIS sensor is about $57 \mathrm{mV} / \mathrm{pH}$, this signal shift corresponds to a local $\mathrm{pH}$ change near the surface of the $\mathrm{pH}$-sensitive layer of $\Delta \mathrm{pH} \sim 0.25$.

As can be seen from Fig. $5 \mathrm{a}$, with ascending and descending $\mathrm{H}_{2}$ dosages, a good correlation between the ConCap response of the field-effect sensor and the output signal of the amperometric sensor has been observed. The respective calibration curves of the sensors evaluated from Fig. 5a are presented in Fig. 5b. Both the amperometric and the field-effect transducer show a linear response in the $\mathrm{H}_{2}$ concentration range from 0.1 to $3 \%(v / v)$ with a


Fig. 5. Simultaneous amperometric/field-effect detection of dissolved $\mathrm{H}_{2}$ in the concentration range from 0.05 to $3 \%(v / v) \mathrm{H}_{2}$ (a) and calibration curves of both the amperometric and the field-effect transducer, respectively (b).

$\mathrm{H}_{2}$ sensitivity of $198.4 \pm 13.7 \mathrm{nA} / \%(\mathrm{v} / \mathrm{v})$ and $14.9 \pm 0.5 \mathrm{mV} / \%(\mathrm{v} / \mathrm{v})$, respectively. The lower detection limit has been estimated to be about $0.05 \%(\mathrm{v} / \mathrm{v})$ and $0.1 \%(\mathrm{v} / \mathrm{v})$ for the amperometric and fieldeffect sensor, respectively. Both transducers displayed practically no hysteresis (less than $2 \mathrm{nA}$ for the amperometric transducer and $\sim 0.35 \mathrm{mV}$ for the field-effect device). The noticeable increase of noise in the amperometric sensor signal at high $\mathrm{H}_{2}$ concentrations might be probably due to the rather random flow conditions at the Pt working electrode during the $\mathrm{H}_{2}$ gassing.

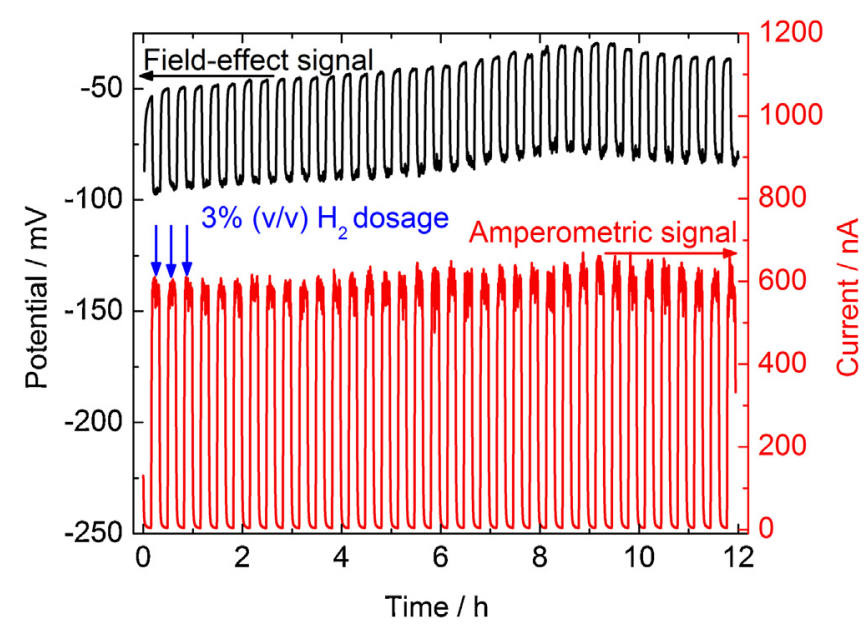

Fig. 6. Amperometric and field-effect responses of the combined sensor chip to $3 \%$ (v/v) $\mathrm{H}_{2}$ dosage over a substantial number of measuring cycles (36 cycles). 
Fig. 6 shows the amperometric and field-effect responses of the combined sensor chip to $3 \%(\mathrm{v} / \mathrm{v}) \mathrm{H}_{2}$ dosage over a substantial number of measuring cycles ( 36 cycles). Almost identical maximum output currents of approximately $580 \mathrm{nA}$ were observed for the amperometric sensor over the whole measuring period, showing the stability and reproducibility of the developed sensor. The output signal of the field-effect EIS sensor changes about $45 \mathrm{mV}$ in the direction corresponding to lower $\mathrm{pH}$ values. Whereas the amperometric signal was very stable, a relatively small drift about $2.5 \mathrm{mV} / \mathrm{h}$ was observed for the field-effect sensor.

\section{Conclusions}

In the present work, a one-chip integrated combined amperometric/field-effect $\mathrm{H}_{2}$ sensor has been developed and tested in electrolyte solutions with different contents of dissolved $\mathrm{H}_{2}$. Both the amperometric and the field-effect transducer show a linear response in the $\mathrm{H}_{2}$ concentration range from 0.1 to $3 \%(\mathrm{v} / \mathrm{v})$ with a slope of $198.4 \mathrm{nA} / \%(\mathrm{v} / \mathrm{v})$ and $14.9 \mathrm{mV} / \%(\mathrm{v} / \mathrm{v})$, respectively. With increasing or decreasing $\mathrm{H}_{2}$ dosages, a good correlation between the ConCap response of the field-effect transducer and the output signal of the amperometric transducer has been observed.

The obtained results demonstrate the independent functioning of both transducer principles on the same chip as well as the feasibility of the presented approach for a simultaneous amperometric/field-effect detection of dissolved $\mathrm{H}_{2}$. Such a combination of two transducer principles, namely, the amperometric and field-effect, might allow a more accurate, selective and reliable measurement of dissolved $\mathrm{H}_{2}$ in biogas reactors and can serve as an early warning indicator of digester failures.

To overcome possible problems related to the functioning of the combined sensor in real biogas broths, future work will be directed to a direct coupling of the sensor setup with a biogas reactor via a bypass system filled with a suitable buffer solution, which will be separated from the biogas medium by a $\mathrm{H}_{2}$-permeable membrane (of e.g., polytetraflouroethylane). In this way, the selectivity, lifetime and signal-to-noise ratio of the combined sensor can be improved. Moreover, to achieve a high output signal for the field-effect $\mathrm{pH}$ sensor, the bypass system can be filled with an appropriate low-capacity internal buffer solution.

\section{Acknowledgement}

The authors gratefully thank the Bundesministerium für Bildung und Forschung (BMBF, Germany) for financial support of this work (EMSiG).

\section{References}

[1] A. Demirbaş, Biomass resource facilities and biomass conversion processing for fuels and chemicals, Energy Conversion and Management 42 (2001) 1357-1378.

[2] R. Cord-Ruwisch, T.I. Mercz, C.-Y. Hoh, G.E. Strong, Dissolved hydrogen concentration as an on-line control parameter for the automated operation and optimization of anaerobic digesters, Biotechnology and Bioengineering 56 (1997) 626-634.

[3] P. Weiland, Biogas production: current state and perspectives, Applied Microbiology and Biotechnology 85 (2010) 849-860.

[4] B.K. Ahring, Perspectives for anaerobic digestion, in: B.K. Ahring, I. Angelidaki, E.C. Macario, H.N. Gavala, J. Hofman-Bang, A.J.L. Macario, S.J.W.H.O. Elferink, L. Raskin, A.J.M. Stams, P. Westermann, D. Zheng (Eds.), Advances in Biochemical Engineering/Biotechnology, Springer, Berlin, Heidelberg, 2003, pp. 1-30.

[5] D.B. Archer, M.G. Hilton, P. Adams, H. Wiecko, Hydrogen as a process control index in a pilot scale anaerobic digester, Biotechnology Letters 8 (1986) 197-202.

[6] D. Lloyd, T.N. Whitmore, Hydrogen-dependent control of the continuous thermophilic anaerobic digestion process using membrane inlet mass spectrometry, Letters in Applied Microbiology 6 (1988) 5-10.

[7] S.R. Harper, F.G. Pohland, Recent developments in hydrogen management during anaerobic biological wastewater treatment, Biotechnology and Bioengineering 28 (1986) 585-602.
[8] A. Pauss, G. Andre, M. Perrier, S.R. Guiot, Liquid-to-gas mass transfer in anaerobic processes: inevitable transfer limitations of methane and hydrogen in the biomethanation process, Applied and Environment Microbiology 56 (1990) $1636-1644$.

[9] G.E. Strong, R. Cord-Ruwisch, An in situ dissolved-hydrogen probe for monitoring anaerobic digesters under overload conditions, Biotechnology and Bioengineering 45 (1995) 63-68.

[10] L. Björnsson, E.G. Hörnsten, B. Mattiasson, Utilization of a palladium-metal oxide semiconductor (Pd-MOS) sensor for on-line monitoring of dissolved hydrogen in anaerobic digestion, Biotechnology and Bioengineering 73 (2001) 35-43.

[11] K. Kuroda, R. Gaiger Silveira, N. Nishio, H. Sunahara, S. Nagai, Measurement of dissolved hydrogen in an anaerobic digestion process by a membrane-covered electrode, Journal of Fermentation and Bioengineering 71 (1991) 418-423.

[12] J.-C. Frigon, S.R. Guiot, Impact of liquid-to-gas hydrogen mass transfer on substrate conversion efficiency of an upflow anaerobic sludge bed and filter reactor, Enzyme and Microbial Technology 17 (1995) 1080-1086.

[13] E.G. Hörnsten, I. Lundström, A. Nordberg, B. Mathisen, The use of palladium metal oxide semiconductor structures in quantitative studies of $\mathrm{H}_{2}$ and $\mathrm{H}_{2} \mathrm{~S}$ in processes related to biogas production, Bioprocess Engineering 6 (1991) 235-240.

[14] D. Lloyd, R.I. Scott, T. Williams, Membrane inlet mass spectrometry-measurement of dissolved gases in fermentation liquids, Trends in Biotechnology 1 (1983) 60-63.

[15] M. Sakthivel, A portable limiting current solid-state electrochemical diffusion hole type hydrogen sensor device for biomass fuel reactors: engineering aspect, International Journal of Hydrogen Energy 33 (2008) 905-911.

[16] A. Pauss, S.R. Guiot, Hydrogen monitoring in anaerobic sludge bed reactors at various hydraulic regimes and loading rates, Water Environment Research 65 (1993) 276-280.

[17] A. Pauss, R. Samson, S.R. Guiot, C. Beauchemin, Continuous measurement of dissolved $\mathrm{H}_{2}$ in an anaerobic reactor using a new hydrogen/air fuel cell detector, Biotechnology and Bioengineering 35 (1990) 492-501.

[18] J.K. Kristjansson, P. Schönheit, R.K. Thauer, Different $K_{s}$ values for hydrogen of methanogenic bacteria and sulfate reducing bacteria: an explanation for the apparent inhibition of methanogenesis by sulfate, Archives of Microbiology 131 (1982) 278-282.

[19] K. Nakazato, An integrated ISFET sensor array, Sensors 9 (2009) 8831-8851.

[20] J.R. Siqueira, M.H. Abouzar, A.S. Poghossian, V. Zucolotto, O.N. Oliveira, M.J. Schöning, Penicillin biosensor based on a capacitive field-effect structure functionalized with a dendrimer/carbon nanotube multilayer, Biosensors and Bioelectronics 25 (2009) 497-501.

[21] C.-S. Lee, S.K. Kim, M. Kim, Ion-sensitive field-effect transistor for biological sensing, Sensors 9 (2009) 7111-7131.

[22] J. Gun, M.J. Schöning, M.H. Abouzar, A.S. Poghossian, E. Katz, Field-effect nanoparticle-based glucose sensor on a chip: amplification effect of coimmobilized redox species, Electroanalysis 20 (2008) 1748-1753.

[23] F. Patolsky, G. Zheng, C.M. Lieber, Nanowire-based biosensors, Analytical Chemistry 78 (2006) 4260-4269.

[24] A.S. Poghossian, S. Ingebrandt, A. Offenhäusser, M.J. Schöning, Field-effect devices for detecting cellular signals, Seminars in Cell and Developmental Biology 20 (2009) 41-48.

[25] Y. Mourzina, T. Mai, A.S. Poghossian, Y. Ermolenko, T. Yoshinobu, Y. Vlasov, H. Iwasaki, M.J. Schöning, $\mathrm{K}^{+}$-selective field-effect sensors as transducers for bioelectronic applications, Electrochimica Acta 48 (2003) 3333-3339.

[26] C. Huck, P. Jolly, P. Wagner, A.S. Poghossian, M.J. Schöning, One-chip integrated dual amperometric/field-effect sensor for the detection of dissolved hydrogen, Procedia Engineering 25 (2011) 1161-1164.

[27] T. Hübert, L. Boon-Brett, G. Black, U. Banach, Hydrogen sensors-a review, Sensors and Actuators B157 (2011) 329-352.

[28] M. Sakthivel, W. Weppner, Development of a hydrogen sensor based on solid polymer electrolyte membranes, Sensors and Actuators B113 (2006) 998-1004.

[29] J.R. Stetter, J. Li, Amperometric gas sensors-a review, Chemical Reviews 108 (2008) 352-366.

[30] Y. Chao, S. Yao, W.J. Buttner, J.R. Stetter, Amperometric sensor for selective and stable hydrogen measurement, Sensors and Actuators B106 (2005) 784-790.

[31] A.S. Poghossian, L. Berndsen, M.J. Schöning, Chemical sensor as physical sensor: ISFET-based flow-velocity, flow-direction and diffusion-coefficient sensor, Sensors and Actuators B95 (2003) 384-390.

[32] W. Olthuis, J. Luo, B. van der Schoot, P. Bergveld, M. Bos, W. van der Linden, Modelling of non-steady-state concentration profiles at ISFET-based coulometric sensor-actuator systems, Analytica Chimica Acta 229 (1990) 71-81.

[33] A.S. Poghossian, The super-Nernstian pH sensitivity of $\mathrm{Ta}_{2} \mathrm{O}_{5}$-gate ISFETs, Sensors and Actuators B7 (1992) 367-370.

[34] M.J. Schöning, D. Brinkmann, D. Rolka, C. Demuth, A.S. Poghossian, CIP (cleaning-in-place) suitable non-glass pH sensor based on a $\mathrm{Ta}_{2} \mathrm{O}_{5}$-gate EIS structure, Sensors and Actuators B111/112 (2005) 423-429.

[35] T. Setoguchi, Effects of anode material and fuel on anodic reaction of solid oxide fuel cells, Journal of the Electrochemical Society 139 (1992) 2875-2880.

[36] S.P. Jiang, Hydrogen oxidation at the nickel and platinum electrodes on yttriatetragonal zirconia electrolyte, Journal of the Electrochemical Society 144 (1997) 3777-3784.

[37] J. Luo, W. Olthuis, P. Bergveld, M. Bos, W. van der Linden, Determination of buffer capacity by means of an ISFET-based coulometric sensor-actuator system with a gate-covering porous actuator, Sensors and Actuators B20 (1994) $7-15$. 
[38] A. Soldatkin, D.V. Gorchkov, C. Martelet, N. Jaffrezic-Renault, Application of charged polymeric materials as additional permselective membranes for modulation of the working characteristics of penicillin sensitive ENFETs, Materials Science and Engineering C5 (1997) 35-40.

[39] T. Yoshinobu, H. Ecken, A.S. Poghossian, A. Simonis, H. Iwasaki, H. Lüth, M.J. Schöning, Constant-current-mode LAPS (CLAPS) for the detection of penicillin, Electroanalysis 13 (2001) 733-736.

[40] C. Cané, I. Gràcia, A. Merlos, Microtechnologies for pH ISFET chemical sensors, Microelectronics Journal 28 (1997) 389-405.

[41] A.S. Poghossian, Determination of the pHpzc of insulators surface from capacitance-voltage characteristics of MIS and EIS structures, Sensors and Actuators B44 (1997) 551-553.

\section{Biographies}

C. Huck studied physical engineering at Aachen University of Applied Sciences, Campus Jülich, from 2005 to 2009. She received her diploma degree in 2009. Following, she started her PhD thesis at the Institute of Nano- and Biotechnologies (Laboratory of Chemical Sensors and Biosensors) at the Aachen University of Applied Sciences. Her research subjects concern (bio-)chemical sensors, especially hydrogen sensors.

A. Poghossian received his PhD degree in solid-state physics from Leningrad Electrotechnic Institute in 1978 and the Dr. Sci. degree in solid-state electronics and microelectronics from the State University of Yerevan (Armenia) in 1995. After being an associate professor of State Engineering University of Armenia and director of Microsensor Ltd. (Yerevan) from 1991 to 1996, he has been a full professor at the University of Management and Information (Yerevan). Since 1998, he has been with the Institute of Thin Films and Interfaces (now, Peter Grünberg Institute-8) at the Research Centre Jülich, and since 2004, he joined the Institute of Nano- and Biotechnologies at Aachen University of Applied Sciences, Germany. In 2008, he has been appointed as Honorary Professor. His research interests are solid-state chemical sensors and biosensors, sensor materials, nano-devices, microsystem technology, nano- and biotechnology.

P. Wagner obtained his PhD in 1994 at Technical University Darmstadt (Germany) in experimental solid-state physics with a focus on cuprate superconductors. From 1995 until 2001, he was postdoctoral researcher in the Laboratory of SolidState Physics and Magnetism at Catholic University Leuven (Belgium), where he studied the magneto-transport properties of mixed-valency magnetic oxides. Since 2001, he is a professor of physics at Hasselt University (Belgium) and responsible for the development of label-free readout techniques for DNA-, protein-, and small-molecule sensors. Patrick Wagner is recipient of a WE Heraeus award, a Marie-Curie Fellowship of the European Union, a Methusalem Grant of the Flemish Government and is past president of the Belgian Physical Society.

MJ. Schöning received his $\mathrm{PhD}$ in 1993 at Karlsruhe University of Technology in the field of semiconductor-based microsensors for the detection of ions in liquids. From 1993 until 1999, he has been with the Institute of Thin Films and Interfaces (now, Peter Grünberg Institute-8) at the Research Centre Jülich, and since 1999, he was appointed as full professor at Aachen University of Applied Sciences, Campus Jülich. Since 2006, he serves as a director of the Institute of Nano- and Biotechnologies (INB) at the Aachen University of Applied Sciences. His main research subjects concern silicon-based chemical and biological sensors, thin-film technologies, solid-state physics, microsystem and nano(bio-)technology. 